\section{SOME LECTURE NOTES UPON METEORITES}

NOWHERE in the "Cosmos" does Alexandex ron Humboldt show more vividly his keen appreciation of all the grander operations of nature than in those passages in which he discusses the subject of meteors, and in which he gives us a forecast of the connection of those striking and still not entirely explained phenomena with other celestial spectacles, such as the apparition of comets and the fall of meteorites.

Thus Humboldt dwells with a lingering interest on the subject of the meteoric showers which in their grandest form, on at least one, and generally $\mathrm{cn}$ some successive Novembers in every generation, and in a less brilliant degree on every Ioth of August, illuminate the sky with countless lines of momentary light. And while bringing the occurrence of these swarms of meteors with much vividness before pour eyes, he treats them as a special form of the same display presented by the single meteor, that, gliding down the sky, leaves its thread of light to illuminate a few degrees of the great arc described on the dome of heaven by the meteor; nor does he hesitate to link these pheno. mena into one series with those larger meteoroids that we call fireballs, and which sometimes light up the whole licavens, and may occasionally be seen over half a continent. And we may go cn with Humboldt to connect with these greater meteors a class of still more striking phenomena accompanying the descent generally out of a dark cloud when seen in daylight, or with a bright flame, when scen by night, of meteoric stones, heralded by sounds as of thunder.

Within the last fow years the cases of recurring periods of meteoric showers have been considerably multiplied, while these and the comets have been recognised by astronomers as belonging to the same order of celestial objects : and we are now enabled to group the whole of the phenomena we are considering under a single category with a confidence far greater than that on which Humboldt built his surmise regarding them.

It is with the meteoric bodies that fall from out of a cloud when scen by day, and in fiery mass where the light can be distinguished, and accompanied by detonations like cannon, that ive are going more immediately to deal here; and it may be well therefore, without recalling the descriptions that may be found in many treatises of some of the more familiar meteoric falls, such as those of L'Aigle and of Braunau, to recount the evidence of eye-witnesses of these events on other occasions. The follow ing is a contemporary account of the fall of a shower of stones in the county of Limerick, at Adare, on Sept. Io, 1813:-

"Friday morning, the roth September, 1813 , being very calm and serene, and the sky clear, about 9 o'clock, a cloud appeared in the east, and very soon after I heard eleven oistinct reports, appearing to proceed thence, somewhat resembling the discharge of heavy artillery. Immediately after this followed a considerable noise not unlike the beating of a large drum, which was succeeded by an uproar resembling the continued clischarge of musketry in line. The sky above the place whence this noise appeared to issue became darkened and very much disturbed, making a hissing noise, and from thence appeared to issue with great violence different masses of matter, which directed their course with great velocity in a horizontal direction towards the west. One of these was observed to descend; it fell to the earth, and sank into it more than a foot and a balf, on the lands of Scagh, in the neigh. bourhood of Patrick's Well, in the county of Limerick. It was immediately dug up, and I have been informed by those that were present, and on whom I could rely, that it was then warm, and had a sulphurous smell. It weighed about $17 \mathrm{lbs}$., and had no appearance of having been fractured in any part, for the whole of its surface was uniformly smooth and black, as if affected by sulphur or gunpowder. Six or seven more of the same kind of masses, but smaller, and fraclured, as if shattered from each other or from larger ones, descended at the same time with great velocity in different places between the lands of Scagh and the village of Adare, One more very large mass passed with great rapidity and considerable noise at a small distance from me; it came to the ground on the lands of Brasky, and penetrated a very hard and dry earth about two feet. This was not taken up for two days; it appeared to be fractured in many places, and weighed about $65 \mathrm{lbs}$.! Its shape was rather round, but irregular. It cannot be ascerfained whether the small fragments which came down at the same time corresponded with the fractures of this large stone in shape or number, but the unfractured part of the surface has the same appearance as the one first mentioned. There fell also at the same time, on the lands of Falia, another stone, which does not appear to have been part of or separated from any other mass; its skin is smooth and blackish, of the same appearance with the firsi-mentioned; it weighed above $74 \mathrm{lbs}$; its shape was vexy irregular. This stone is in my possession, and, for its volume, is very heavy.

"There was no flash of lightning at the time of, or immediately before, or after the explosion; the day continued very calm and serene, was rather close and sultry, and without wind or rain. It is about three miles in a direct line from the lands of Brasky, where the very large stone descended, to the place where the small ones fell in Adare, and all the others fell intermediately; but they appeared to descend horizontally, and as if discharged from a bomb and scattered in the air."

The next account is that of a stone that fell at Duraja, or Dooralla, on February 18 , I815.

\section{Extracts from a Letter jron Cast. G. Bird. \\ " Locdiana, April 5, 1815.}

"On the I8th February last, some people who were at work in a field about half a mile distant from the villace of Dooralla were suddenly alarmed by the explosion of what they conceived to be a large cannon, 'the report keing louder than that of any other gun they had ever heard,' which report was stcceeded by a rushing noise like that of a canncn ball in its grealest force. When looking towards the quarter whence the noise proceeded, they perceived a large black body in the air; apparently moving directly towards them, but, passing with inconceivable velocity, buried itself in the earth at the distance of about Go paces from the spot where they stood. The Brahmins of the village, hearing of it, proceeded to the spot with tools for digging it up. They found the surface broken, and the fresh earth and sond thiown about to a considerable distance, ard at the depth of a ather nicre than $5 \mathrm{ft}$. in a soil of mingled sand and lcam they found the stone, which they cannot coubt was what actually fell, bcing altogether unlike anything known in that part of the country. The BrahInins conveyed it to the village, covered it with wreaths of flowers, and started a subscription for the purpose of raising a small temple over it. It fell on the I8th of February, about mid-day, in a field near the village of Dooralla, which lies atout lat. $30^{\circ}$ $20^{\prime}$, long. $76^{\circ} 41^{\prime}$, within the territory belonging to the Fattialah Rajah, 16 or 17 miles from Umballa, and 80 from Locdiana. The day was very clear and serene, and, as uswal at that season of the year, not a cloud was tc be $s \in \varepsilon n$, nor was there in the temperature of the air anything tc engage their attention; the thermometer of course may be stated about $68^{\circ}$ in the shade. The report was heard in all the circumjacent towns and villages, to the distance of 20 coss, or 25 miles, from Dooralla. The Rajah having been led to consider it as a messenger of $i l l$ omen, according to my wish gave immediate orders for its conveyance to Loodiana, but with positive injunctions that it should not apprcach his place of residence. It weighs rather more than $25 \mathrm{lbs}$., and is covered with a pellicle thinner than a wafer, of a black sulphureous crust, though it emits no smell of sulphur that I can discover. It is an ill-shapen triangle, and from one of the crr. ners a piece has been brcken off, either in its fall or by the in. struments when taken out of the ground. This fracture discloses a view of the interior, in which ircn pyrites and nickel are distinctly visible. No Hindoo ventures to appreach it but with closed hands in apparent devction, so awful a matter is it in their eyes."

This aërolite was brought from India by Lieut.-Col. Pennington, and presented to the Hon. East India Company. It is now in the British Museum.

The next description is that of the fall of a stone at Manegaum, in Kandeish, on June 29, 1843. The account is given by two Hindoo eye-witnesses :-

"On the day the aërolite fell we were both seated, about 3 o'clock in the aftemoon, on the outskirts of the village, in a shed belonging to Ranco Patel. There was at the time no rain, but heavy clouds towards the northward. There had been several claps of thunder for two hours previously, and some lightning. Suddenly, while we were seated in the shed, several very heavy claps of thunder occurred in quick succession, accompanied with lightning, on which we both went cut to look around us, when, in the middle of a heavy clap, we saw a stone fall to the ground in a slanting direction from north to south, preceded by a flash of lightning. It fell about 50 paces from us. On going up to it we found that it had indented itself some four or five inches into the ground ; it was broken in pieces, and, as far as we could judge, appeared to be about fifteen inches long, and three inches in diameter, of an oblong shape, somewhat similar to a Chouthe grain 
measure; it was of a black vitreous colour outside, and of a greyish yellow inside; it was then of a mouldy texture, and hardened to the consistence of the present specimens afterwards.

"Only one stone fell. No rain had fallen for eight days previously, nor did it for four days after the fall of the stone. It had been warm all day before, but not much more so than usual. From mid-day till the time the stone fell (3 P.M.) it was very cloudy towards the northward; after its fall the thunder ceased, and the clouds cleared away. No stone of a similar description had ever fallen near our village before. The pieces of the stone were immediately after carried off by the country people. Our village is situated on the banks of the small river, the Poorma. There are no hills in its vicinity, the nearest being 3 coss (or 6 miles) off."

Finally, we may extract from the contemporary notices pub. lished in the United States, the more remarkable circumstances attending the fall of a great number of aèrolites at New Concord, U.S.A. :-

"About fifteen minutes before one o'clock, May I, I860, the people of South-eastern Ohio and North-eastern Virginia were startled by a loud noise. . . . The area over which the explosion was heard was probably not less than 150 miles in diameter. - . . . An examination of all the different directions leads to the conclusion that the central point from which the sound emanated was near the southern part of Noble County, Ohio.

"Twenty-three distinct detonations were heard, after which the sounds became blended together, and werecompared to the rattling fire of an awliward squad of soldiers, and by others to the roar of a railway train. These sounds, with their reverberations, are thought to have continued for two minutes. The last sounds scemed to come from a point in the south-east, $45^{\circ}$ below zenith. The result of this cannonading was the falling of a large number of stony meteorites upon an area of about ten miles long by three wide. The sky was cloudy, but some of the stones were seen first as 'black specs,' then as 'black birds,' and fmally falling to the ground. A few were picked up within twenty or thirty minutes. The warmest was no warmer than if it had lain on the ground exposed to the sun's rays. They penetrated the earth from $2 \mathrm{ft}$. to $3 \mathrm{ft}$. The largest stone, which weighed ro3 lbs., struck the earth at the foot of a large oak tree, and after cutting off two roots, one $5 \mathrm{in}$. in diameter, and grazing a third root, it descencled $2 \mathrm{ft}$. $10 \mathrm{in}$, into hard clay. This stone was found resting under a root which was not cut off. This would seemingly imply that it entered the earth obliquely. It is said that other stones which fell in soft ground entered the earth at a similar angle. They must have been flying in a north-west direction. This fact, added to the other facts, that the detonations heard at New Concord came lower and lower from the zenith toward the soutl-east, and that the area upon which the stones fell extends with its longer axis in a south-east and north-west direction, would imply that the orbit of the meteor, of which these stones are fragments, extended from south-east to north-west. This conclusion is confirmed by the many witnesses who saw at the time a luminous body moving in the same direction. It is a fact of some interest that the larger stones were carried by the orbital force further than the small ones, and were found scattered upon the north-west end of the area referred to.

"Prof. Evans computes, from data supplied by several reliable witnesses, the altitude of the meteor when first seen to range between thirty-seven and forty-four miles.

"A train accompanying the stones is described as a cone, having its base upon a fire-ball. As seen from near Parkersburg its length was estimated at twelve times the diameter of the ball. The part next the base appeared as a white flame, but not so bright as to render the outline of the ball indistinct. About half way toward the apex it faded into a steel blue.

"Near McConnelisville several boys observed a huge stone descend to the earth which they averred looked like a red ball, leaving a line of smoke in its wake." McConnellsville is twenty. five miles south of Concord.

Another observer at Berlin saw a ball of fire flying in a northerly direction with great velocity. It appeared as white as melted iron, and left a bright streak of fire behind it which soon faded into a white vapour. This remained more than a minute, when it became crooked and disappeared. Berlin is about 80 miles south-west of Concord.
Now, these and other descriptions of similar events witnessed by people in different parts of the world substantially agree. In some minute circumstances they naturally differ, as coubtless do also the events themselves or the conditions under which they are witnessed. The appearance of a cloud at a great elevation, its rapid motion, the emanation from it of masses of matter ulti. mately falling to the earth, the association with these appearances of a fiery light forming a splendid spectacle that lights up the heavens by night and in twilight, and is often also seen by day the trail that follows the great meteoroid mass, and lingers on the air in the form of a long-drawn film of cloud that remains Iuminous by night for some short period after the passage of the luminous ball or cone,--are phenomena to which witness is borne in many cases besides the last above recorded. Testimony is also concurrent on the loudness and repetition of detonations that accompany these phenomena, irrespectively of their multiplication by the effect of echo. In the case of a group of meteorites that fell at Butsura, in India (near Goruckpore), on May I2, 186 I, we have evidence of three different explosions.

Now, for some parts of the phenomena thus recorded we can offer satisfactory explanations, though of other parts of them the explanations hitherto offered may seem not quite so complete.

First, we have the enormous velocity with which such a body comes into our atmosphere, sufficient in some cases to bear the meteorite through the dislance from London to Edinburgh in as many seconds as an express train takes hours; and where the body enters our atmosphere that medium is so rare that we can hardly conceive it presenting any resistance; yet even at that enormous elevation-certainly in many cases as mucl as forty miles above the earth, where the meteor enters this fine atmosphere-there cannot be a doubt that the atmospheric resistance at once called into play is sufficient to impede the body that enters it with so enormous a velocity. And by virtue of a principle which is now an axiom of science, this arresting of the velocity of the meteorite means calling into activity intense lieat that is largely imparted to the meteorite itself - heat, in fact, that is proportional to the velocity for which it is exchanged.

Now, these meteoric masses must often come into our atmosphere, not individually, but in swarms. From the rapidity with which the heat is developed, and partly also as a consequence of the low conductivity for heat of the stony masses, their surface only has time to experience the effects in the few seconds of transit, and therefore only the surface fuses; and, as a consequence of this fusion, there arises a sort of spray of meteoric dust flung off from the meteorite or from the meteoric swarm; and this forms a cloud, such as may be seen lingering on the track of almost any large meteor that is visible by daylight. To the material nature of such a cloud as it rests, or rather, though rapidly falling, seems to rest, poised in the air, the writer can bear personal testimony, having witnessed it in the train of a fine meteor many years ago, about sunset. When the ordinary clouds had long ceased to be tinted by the rays of the evening sun, as in the after-glow on the Alps, the long line of meteoric cloud became lit up with rose-tinted hues, and bending into a curve towards the east before an upper current of air, offered proof beyond question of the material nature of this cloud, and at the same time of its great elevation and the fine state of division of its dust-like particles, which undoubtedly resulted from the disintegtation of the meteoric mass in its passage through the air. The same cloud of dust is often visible as a Iuminous trail by night, in consequence partly of its retaining its incandescence for a certain time, but probably also in part from the phosphorescence of its material. We are thus able to offer an undoubtedly true explanation of one part of the spectacle.

The existence in the crust of a meteorite of projecting particlcs of unoxidised meteoric iron, and, in the case of the Busti meteorite, of calcium sulphide unaltered, is explained by the momentary character of the process which during the flight of the meteorite perpetually removes the outer surface and exposes a fresh one, which, however, is always screened by a protecting glaze of fused silicate from the immediate action of the air, so long as there is velocity enough left to the mass thus to fuse and to throw off in its wake fresh portions of its surface; while in the later stage of its flight the glaze accumulates into a denser crust highly charged with magnetic iron oxide, mainly the result of the oxidation of the iron of the silicates.

The cause or causes of the explosions are more difficult to demonstrate. They have been accounted for in two separate ways, which, though different, are not inconsistent, and are both probably involved in a complete explanation of the disruption and detonations. Why should a meteorite explode with a repor 
which could be heard forty or fifty miles away? Nay, why should it explode at all?

One answer is this. The aerolite comes into our atmosphere from regions in which the temperature, "the cold of space," may range as low as $140^{\circ}$ below zero Centigrade; and though the mass, from the absorption of solar heat, would possess a temperature much above this, it would nevertheless be intensely cold, and consequently more brittle than at ordinary temperatures ; and hence, on its entering our atmosphere, the heat it instantaneously acquires on its outer portion expands this, and tends to tear it away, so as to dissever the exterior from the interior, which continues to be relatively contracted by the intensity of the cold which the aërolite brings with it from space. The consequence is, first, that little bits of the stone spring out all over it, leaving those curious little holes or pit marks which are characteristic of a meteorite; and every now and then, as the heat penetrates, larger masses split away, of which interesting eviclence is afforded by the meteorite, for instance, that fell at Butsura on May 12, I86r. Fragments of this stone were picked up three or four miles apart; and by supplementing them by a small piece modelled to fill up one lacuna, one is able to build up again with much certainty the original meteorite, or at least the portion of it represented by the fragments of it which were found. Im. portant portions of this stone are in the British Museum, presented some years ago by the liberality of that invaluable institution, the Asiatic Society of Calcutta. Now, it is remarkable that these fragments, which in other respects fit perfectly together, are, even on the faces of junction, now coated with a black crust. On the other hand, another of these fragments not thus coated fits like the former to a part of the meteorite that was found some miles away rom it, and is also not incrusted at the surface of fracture. Hence we can assert that this aërolite acquired after coming into our at mosphere a scoriated and blackened surface or incrustation. The first explosion drove the framments first alluded to asunder, and these became at once incrusted on their broken surfaces; but others that were separated afterwards, probably on the last of the three explosions, had not sufficient velocity left to cause their in. crustation in the same manner as was the case with the fragments previously severed. Now, this successive incrustation of the fragments of the meteorite confirms the idea that the disruption of the mass, and the explosions heard for so vast a distance as Goruckpore (some sixty mi!es), are parts of the same convulsion; and sixty miles is by no means an uncommon distance for the sound of such a meteoric explosion to be heard.

The late W, von Haidinger (to whom we are indebted for a collation of the facts and for valuable suggestions bearing on this subject) threw out the notion that what really produced the detonation was not the disruption of the mass (which he held not to be a sufficient cause for so loud a report) so much as the collapse of the air into a vacuum which, after following the meteorite as it pursued its rapid course, suddenly ceased to exist as the velocity of the meteorite became practically reduced to zero.

But it still would remain to be explained why at one time more than another this collapse of the vacuum should take place, or how it could be repeated ; of this, however, a sufficient explanation would seem to be afforded by the actual bursting asunder of the meteorite from the cause before assigned, since this explosion, by disturbing the conditions on which the persistence of the vacuum depends, would permit the collapse of the air and consequent detonation.

(To be continused.)

\section{OBSERVATIONS ON A REMARKABLE FOR- $M A T I O N$ OF CLOUD AT THE ISLE OF $S K Y E^{*}$}

THE resistance offered by the earth's surface to the wind is known to reduce its velocity and to cause deriations in its direction both horizontal and vertical, as well as to retard the progress of the storm itself. This friction to which aërial currents are subjected is probably least for a surface of water such as the sea-greater for plains of loose sand, where, as in the Nubian deserts, lofty sand pillars are produced-and greater still where the surface is immoveable, as in the case of solid land; but the greatest resistance of all is due to the obstruction offered by rugged hills and lofty mountain-ranges.

In an account of the Morayshire easteriy storm of September 1871 ; published in the Scottish Meteorologizal fournal, I sug. gested that the great amount of rainfall which fell on that occa- sion at and near the Morayshire coast, and on the sea-coasts of the counties of Fife and East Lothian which also fronted this storm, was due to the sudden increase of friction which the wind encountered when it reached the land. The in-shore stream of air being checked by the unyielding nature of the shore, even though it was, as in this case, of no great elevation, would form a pillow of obstructed or perhaps nearly stationary air, which would produce vertical deflection on the strong currents coming in from the sea. The stream of air thus projected upwards to a height where the temperature is lower would be condensed into vapour and rain.

This sudden change of resistance to in-shore winds is probably one of the causes of the well-known peculiarity of seaside climates.

On the 27 th July last, about I1.30 A.M., when in the steamer of the Northern Lighthouses of the Sound of Harris, I saw a beantiful example of the genesis of c'nuds-Aue, however, not to

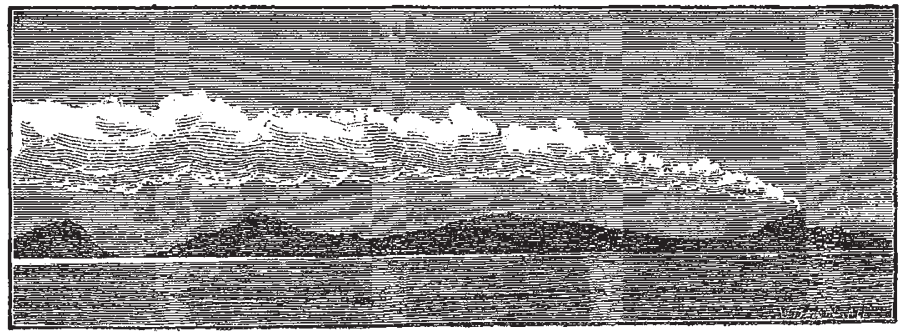

a low foreshore, but to hills of about 900 feet high. The sky was perfectly clear, with a steady but very slight breeze from the S.W., which came straight upon the south-western extremity of the Island of Slkye, distant about twelve miles from the ship. A small portion of the most southerly projection of the island, which was considerably lower than the more inland parts, was perfectly free from vapour, but at a short distance inland from the shore, there was an abrupt face of hill, from the top of which there rose a very slender column of white vapour which gradually expanded as it ascended into the air, presenting exactly the appearance of the escape of steam from the spiracle of a volcano. The cloud thus formed not only extended as far as the northern extremity of Skye-itself a distance of twenty-eight miles-but

\footnotetext{
* By Thomas Stevenson, F.R.S.E.
}

was visible as a well.defined stratum of cloud for a long distance beyond Skye, so that its whole length must have considerably exceeded forty miles, beyond which distance it became more diffuse and attenuated. Had I not known to the contrary, I should undoubtedly have belleved that what I saw was due to volcanic eruption.

The vapour caused by the lower temperature of the atmosphere at the level of the top of the bluff face was obviously carried away by the breeze gradually as it was formed, thus producing by a continuous process of generation the long extert of cloud which I have described. This fact shows that clouds may be due to deflections produced by irregularities on the earth's surface far remote from the place where we actually see them. I may mention, in pronf of the steady nature of the breeze and of the entire absence of any vertical disturbance in 